\title{
Expanding the Organ Donor Pool: Using En Bloc Kidneys in Pediatric Recipients
}

\section{Keith K. Lau ${ }^{1}$ and Lavjay Butani ${ }^{2 *}$}

${ }^{1}$ Department of Pediatric Nephrology, McMaster University, Hamilton, Ontario, Canada ${ }^{2}$ Department of Pediatric Nephrology, University of California Davis, Sacramento, CA, USA

\section{Introduction}

The demand for renal allografts has so far outstripped the available organ donor pool that the gap between patients awaiting a transplant and those actually receiving a transplant seems to be forever widening. Renal transplantation is the ultimate treatment of choice for patients with end stage renal disease as it offers better long term survival and quality of life compared to dialysis [1]. Children with end stage renal disease are especially vulnerable to the organ shortage, since their psychosocial and neurodevelopmental functioning is adversely affected by the uremic environment and any delay in transplanting them can have long term ramifications. Moreover, pre-emptive transplantation has been shown to improve long term graft survival in children [2] . These considerations have made it critical for health-care providers to minimize wait times on dialysis. Among other strategies, expanding the deceased donor organ pool by using organs from donors previously thought of as unsuitable, has proven to be a successful strategy.

\section{En Bloc Renal Transplantation is a Viable and Safe Option to Reduce Wait Times}

Retrieval of kidneys from young donors for transplantation, either as single kidneys or in an 'en bloc' manner, allows utilization of allografts that were previously abandoned and wasted. While the transplantation of pediatric donor kidneys, especially from donors less than 5 years old, is still limited to a few specialized centers, the practice seems to be increasing as evidence of the successes of this strategy grows [3-7].

Recent reports from various centers have consistently demonstrated a positive experience using en bloc kidneys in pediatric and adult recipients. The graft survival of en bloc kidneys has been at least comparable to standard deceased donor kidneys [4,8-12]. Some studies in fact have shown superior outcomes with en bloc transplants compared to standard deceased donor and even live donor transplants [13-15]. In a recent study from France, researchers compared the graft survival among recipients of en bloc grafts (mean donor age of 15 months) to those receiving standard donor grafts (mean donor age of 38 years); those who received en bloc kidneys fared better than their counterparts, with a 10 year survival of $74 \%$ compared to $58 \%$ [14]. The benefits of superior survival of en bloc grafts over the long haul is especially salient in pediatric patients, as they have a longer life expectancy and hence have more to gain from maximizing graft survival [16].

\section{Advantages of En Bloc over Solitary Grafts from Young or Ideal Donors}

Kidneys from small donors have largely been avoided by the transplant community because of the low nephron mass and a higher risk of vascular complications. Reduce nephron mass renders the graft more prone to early hyper-filtration injury; en bloc grafts with twice the number of nephrons and higher volume may mitigate this risk $[17,18]$. Based on animal studies and experience from clinical settings, en bloc grafts but not ideal single kidney donor grafts, increase in size rapidly to adapt to the host environment $[5,15,19-21]$.
In recipients of pediatric donors kidneys, the absolute Glomerular Filtration Rate (GFR) rose along with patient growth, and higher GFRs were sustained when compared to recipients of adult donor kidneys $[22,23]$. These observations support the use of young donor kidneys into pediatric as opposed to adult recipients since pediatric grafts are better able to acclimatise to the needs of growing children. Although still somewhat contentious, reports, including one using the United Network of Organ Sharing (UNOS) database, suggest an advantage of using of en bloc over single kidneys from young donors [4,24-26].

While early reports of increased vascular complications with en bloc transplantation were discouraging [27-30], recent reports have shown more encouraging outcomes $[5,11,26,31]$. This is likely due to increased experience and improvements in surgical techniques over time, which should help further reduce the skepticism in using young donors for transplantation.

Since follow-up remains relatively limited, many questions still remain unanswered. Chief among these are the sustained ability of en bloc kidneys to maintain GFR and the potential risk of hyperfiltration injury leading to graft loss.

\section{Conclusions}

A growing experience from various transplant centers has demonstrated excellent graft survival of en bloc renal transplants in both children and adults. En bloc transplantation offers the advantages of greater nephron mass compared to solitary allografts and rapid growth in size to match recipient growth. Although this is still a technically demanding procedure and has been performed mostly in experienced transplant centers, recent success should increase the willingness of other centers to follow suit.

\section{References}

1. Wolfe RA, Ashby VB, Milford EL, Ojo AO, Ettenger RE, et al. (1999) Comparison of mortality in all patients on dialysis, patients on dialysis awaiting transplantation, and recipients of a first cadaveric transplant. $\mathrm{N}$ Engl J Med 341: $1725-1730$

2. Butani L, Perez RV (2011) Effect of pretransplant dialysis modality and duration on long-term outcomes of children receiving renal transplants. Transplantation 91: 447-451.

3. Modlin C, Novick AC, Goormastic M, Hodge E, Mastrioanni B, et al. (1996) Long-term results with single pediatric donor kidney transplants in adult recipients. J Urol 156: 890-895.

*Corresponding author: Lavjay Butani, MD, Department of Pediatric Nephrology, University of California Davis, 2516 Stockton Blvd, Sacramento, CA 95817, USA, Tel: 916-734-8118; Fax: 916-734-0629; E-mail: Lavjay.butani@ucdmc.ucdavis.edu

Received May 23, 2012; Accepted May 23, 2012; Published May 29, 2012

Citation: Lau KK, Butani L (2012) Expanding the Organ Donor Pool: Using En Bloc Kidneys in Pediatric Recipients. J Nephrol Therapeut 2:e106. doi:10.4172/21610959.1000e106

Copyright: ( 2012 Lau KK, et al. This is an open-access article distributed under the terms of the Creative Commons Attribution License, which permits unrestricted use, distribution, and reproduction in any medium, provided the original author and source are credited. 
Citation: Milladipour AH, Hemami MR (2012) Renal Function Assessment in Adults with Recurrent Calcium Kidney Stone Disease. J Nephrol Therapeut 2:121. doi:10.4172/2161-0959.1000121

Page 2 of 3

4. Pelletier SJ, Guidinger MK, Merion RM, Englesbe MJ, Wolfe RA, et al. (2006) Recovery and utilization of deceased donor kidneys from small pediatric donors. Am J Transplant 6: 1646-1652.

5. Lau KK, Berg GM, Schjoneman YG, Perez RV, Butani L (2010) Pediatric en bloc kidney transplantation into pediatric recipients. Pediatr Transplant 14: 100 104

6. Moore PS, Farney AC, Sundberg AK, Rohr MS, Hartmann EL, et al. (2006) Experience with dual kidney transplants from donors at the extremes of age. Surgery 140: 597-605

7. Afanetti M, Niaudet $P$, Niel O, Saint Faust M, Cochat $P$, et al. (2012) Pediatric en bloc kidney transplantation into pediatric recipients: the French experience. Pediatr Transplant 16: 183-186.

8. Shapiro R, Vivas C, Scantlebury VP, Jordan ML, Gritsch HA, et al (1996) "Suboptimal" kidney donors: the experience with tacrolimus-based immunosuppression. Transplantation 62: 1242-1246.

9. Hobart MG, Modlin CS, Kapoor A, Boparai N, Mastroianni B, et al. (1998) Transplantation of pediatric en bloc cadaver kidneys into adult recipients. Transplantation 66: 1689-1694.

10. Sánchez-Fructuoso Al, Prats D, Pérez-Contín MJ, Marques M, Torrente J, et al (2003) Increasing the donor pool using en bloc pediatric kidneys for transplant. Transplantation 76: 1180-1184.

11. Bhayana S, Kuo YF, Madan P, Mandaym S, Thomas PG, et al. (2010) Pediatric en bloc kidney transplantation to adult recipients: more than suboptimal? Transplantation 90: 248-254.

12. Keitel E, Fasolo LR, D'Avila AR, Didone EC, Santos AF, et al. (2007) Results of en bloc renal transplants of pediatric deceased donors into adult recipients. Transplant Proc 39: 441-442.

13. Sharma A, Fisher RA, Cotterell AH, King AL, Maluf DG, et al. (2011) En bloc kidney transplantation from pediatric donors: comparable outcomes with living donor kidney transplantation. Transplantation 92: 564-569.

14. Thomusch O, Tittelbach-Helmrich D, Meyer S, Drognitz O, Pisarski P (2009) Twenty-year graft survival and graft function analysis by a matched pair study between pediatric en bloc kidney and deceased adult donors grafts. Transplantation 88: 920-925.

15. Sureshkumar KK, Reddy CS, Nghiem DD, Sandroni SE, Carpenter BJ (2006) Superiority of pediatric en bloc renal allografts over living donor kidneys: a longterm functional study. Transplantation 82: 348-353.

16. Courtney AE, Maxwell AP (2009) The challenge of doing what is right in renal transplantation: balancing equity and utility. Nephron Clin Pract 111: C62-C67.

17. Terasaki PI, Koyama H, Cecka JM, Gjertson DW (1994) The hyperfiltration hypothesis in human renal transplantation. Transplantation 57: 1450-1454.
18. Marañes A, Herrero JA, Marron B, Marques M, Cruceyra A, et al. (1998) Functional glomerular reserve in recipients of en bloc pediatric transplant kidneys. Transplantation 65: 677-680

19. Silber SJ (1974) Renal transplantation between adults and children. Differences in renal growth. JAMA 228: 1143-1145.

20. Nghiem DD, Hsia S, Schlosser JD (1995) Growth and function of en bloc infant kidney transplants: a preliminary study. J Urol 153: 326-329.

21. Provoost AP, de Keijzer MH, Kort WJ, van Aken M, Weyma IM, et al. (1984) The influence of the recipient upon renal function after isogeneic kidney transplantation in the rat. Transplantation 37: 55-62.

22. Dubourg L, Cochat P, Hadj-Aïssa A, Tydén G, Berg UB (2002) Better long-term functional adaptation to the child's size with pediatric compared to adult kidney donors. Kidney Int 62: 1454-1460.

23. Provoost AP, Wolff ED, de Keijzer MH, Molenaar JC (1984) Influence of the recipient's size upon renal function following kidney transplantation. An experimental and clinical investigation. Journal of pediatric surgery 19: 63-67.

24. Dharnidharka fVR, Stevens G, Howard RJ (2005) En-bloc kidney transplantation in the United states: an analysis of united network of organ sharing (UNOS) data from 1987 to 2003. Am J Transplant 5: 1513-1517.

25. Satterthwaite R, Aswad S, Sunga V, Shidban H, Mendez RG, et al. Outcome of en bloc and single kidney transplantation from very young cadaveric donors. Transplantation 63: 1405-1410.

26. Lam VW, Laurence JM, Robertson P, Hawthorne W, Ryan BJ, et al. (2009) En bloc paediatric kidney transplant: is this the best use of a scarce resource? ANZ J Surg 79: 27-32

27. Marques M, Prats D, Sánchez-Fuctuoso A, Naranjo P, Herrero JA, et al. (2001) Incidence of renal artery stenosis in pediatric en bloc and adult single kidney transplants. Transplantation 71: 164-166.

28. Strey C, Grotz W, Mutz C, Pisarski P, Furtwaengler A, et al. (2002) Graft survival and graft function of pediatric en bloc kidneys in paraaortal position. Transplantation 73: 1095-1099.

29. Yagisawa T, Kam I, Chan L, Springer JW, Dunn S (1998) Limitations of pediatric donor kidneys for transplantation. Clin Transplant 12: 557-562.

30. Merkel FK, Matalon TA, Brunner MC, Patel SK, Zahid M, et al. (1994) Is en bloc transplantation of small pediatric kidneys into adult recipients justified? Transplant Proc 26: 32-33.

31. Merkel FK (2001) Five and 10 year follow-up of En Bloc small pediatric kidneys in adult recipients. Transplant Proc 33: 1168-1169. 